

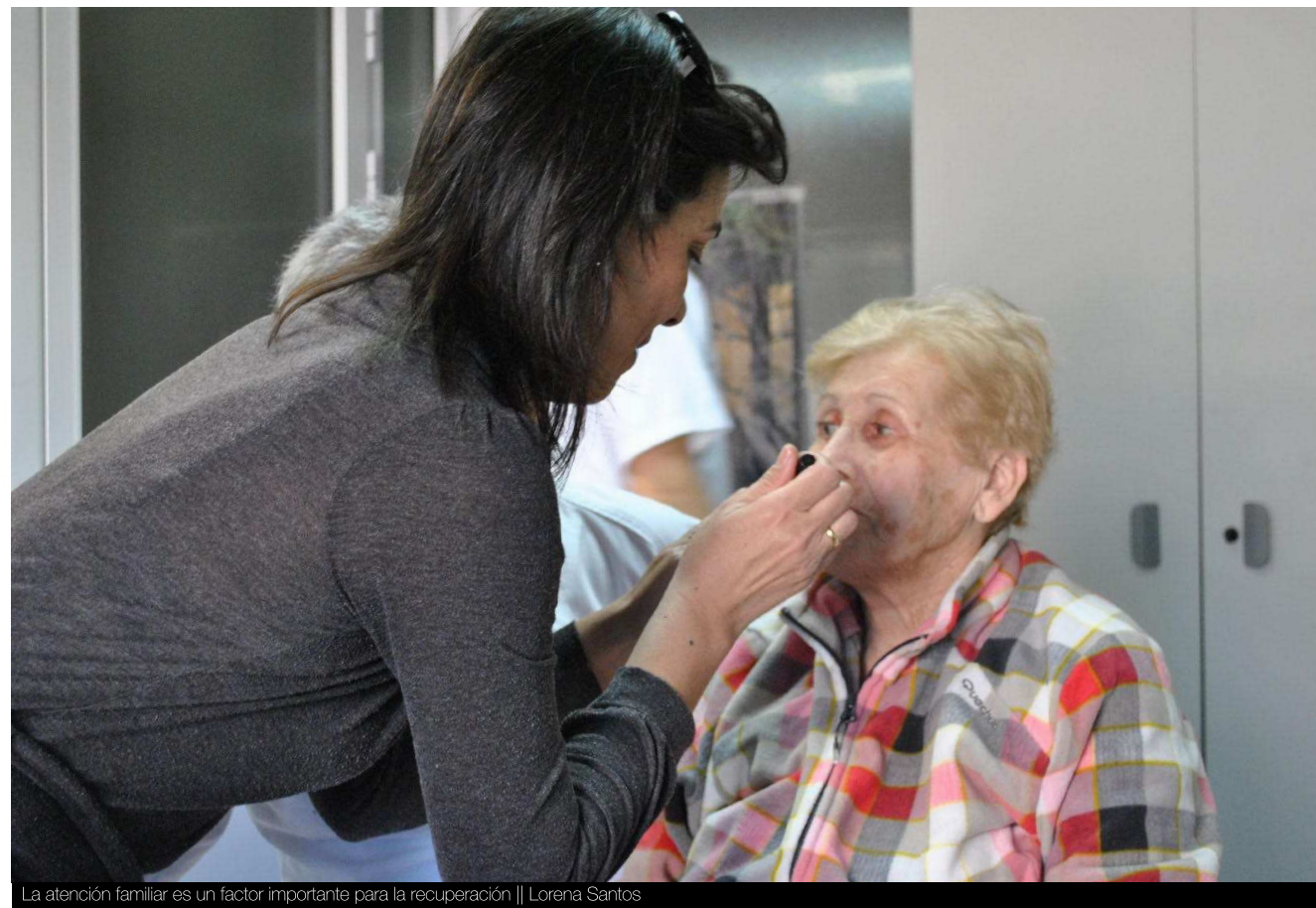

debida a la formación de un coágulo sanguíneo que viaja hasta el cerebro. O bien una embolia grasa; un cúmulo de adipocitos que se desprenden (normalmente tras una fractura ósea) y circulan, también, hasta el cerebro. La gravedad de las lesiones no depende tanto del tipo de ictus, sino del tiempo transcurrido desde que el paciente sufre el ictus hasta que llega al hospital y de la zona del cerebro en que éste se ha producido. Para Manuel Aparicio, el ictus supone trabajo, esfuerzo y superación.

El desconocimiento que existe en torno a las enfermedades cerebrovasculares hace que pocas personas detecten síntomas precoces de esta enfermedad. Sin embargo, sí que los hay: en los ictus hemorrágicos puede aparecer previamente dolor de cabeza y náuseas. Si el ictus es isquémico, puede ir precedido de falta de memoria, confusión y pérdida de movilidad en un miembro, como podría ser la dificultad para mantener firmemente objetos en la mano. En algunos casos, también aparece una l eve desviación de una comisura labial y falta de deglución. Estos signos son motivo suficiente para acudir al médico de inmediato.

\section{Factores de riesgo}

Uno de los principales causantes del ictus es la edad, los accidentes cerebrovasculares son directamente proporcionales a la edad porque los órganos funcionan más lentamente y la sangre se coagula más. Las personas con diabetes, hipertensas o que padecen alguna cardiopatía (infartos, aneurismas o arritmias) presentan un mayor riesgo que el resto de sufrir un infarto cerebral. Sin embargo, existen otras causas que pueden provocar un ictus y se pueden evitar para prevenirlo. La obesidad, la falta de ejercicio, una alimentación desequilibrada, el estrés o el consumo de tóxicos pueden ser determinantes para sufrir un infarto cerebral. "Una alimentación sana, ejercicio moderado y hábitos de vida saludables son la mejor prevención contra el ictus", asevera Aparicio. La educación en salud es un pilar fundamental en la prevención primaria, ya que en los colegios se puede concienciar a los niños sobre la importancia de practicar deporte, de acudir al médico para revisiones regulares y de seguir una dieta saludable.

Según el experto, hoy en día la inversión en prevención es escasa, por lo que no se espera un descenso en los casos de ictus para los próximos años. Aparicio alienta: "Siempre hay recuperación. Si la neurona se ha muerto su función muere con ella, pero gracias a la neuroplasticidad cerebral, otras conectan entre sí para adoptar las funciones de la vieja neurona y así recuperar el movimiento". Para lograr esta recuperación es necesaria la rehabilitación, pero también la actitud. "La concentración del paciente durante los ejercicios que se le proponen, el buen trato por parte del rehabilitador y la implicación de la familia son esenciales para que se produzcan mejoras. Y esto es algo que siempre inculco a mis estudiantes", comenta el profesional.

Cada año, doce estudiantes de último curso de Fisioterapia de la UMH acuden al Hospital General de Alicante para realizar un ciclo de prácticas. En grupos de dos o tres adquieren conocimientos de manos de los diferentes docentes de Fisioterapia de la UMH que trabajan en distintas áreas del hospital: Rehabilitación Cardíaca, Pediatría, Traumatología, Electroterapia y la unidad de Sistema Nervioso Central, para conocer en profundidad el trabajo en cada una de las secciones y adquirir conocimien-

\section{La concentración es esencial para que se produzcan mejoras en el tratamiento}

tos prácticos suficientes para tratar a los pacientes. "Cuando los estudiantes llegan a mi consulta, a primera hora de la mañana, lo primero que hago es una introducción teórica de todos los pasos a seguir. Después, con el paciente presente, les muestro cómo ayudarlo a realizar los movimientos y motivarlo para que él mismo vaya avanzando sesión tras sesión", explica Aparicio. "En la segunda parte de la mañana son los estudiantes los que se ocupan del paciente bajo mi supervisión”, añade.

Cada paciente nuevo significa un reto diferente: una presentación cordial en la primera sesión, una implicación paulatina de la familia y un control continuo y afectivo para que los enfermos se muestren más receptivos y colaboradores. "Personas como Manuel hacen que todo sea más llevadero. Su simpatía y su paciencia nos ayudan mucho moralmente. Nos ha tocado un ángel de la guarda y mi suegra, que es la que sufrió el ictus, cuenta los días para acudir a rehabilitación", expresa la nuera de una de las pacientes. 